Review Article

\title{
The Role of Single Nucleotide Polymorphisms in Predicting Prostate Cancer Risk and Therapeutic Decision Making
}

\author{
Thomas Van den Broeck, ${ }^{1,2}$ Steven Joniau, ${ }^{1}$ Liesbeth Clinckemalie, ${ }^{2}$ Christine Helsen, \\ Stefan Prekovic, ${ }^{2}$ Lien Spans, ${ }^{2}$ Lorenzo Tosco, ${ }^{1}$ Hendrik Van Poppel, ${ }^{1}$ and Frank Claessens ${ }^{2}$ \\ ${ }^{1}$ Department of Urology, University Hospitals Leuven, Herestraat 49, 3000 Leuven, Belgium \\ ${ }^{2}$ Laboratory of Molecular Endocrinology, Department of Cellular and Molecular Medicine, KU Leuven, \\ Campus Gasthuisberg O\&N1, P.O. Box 901, Herestraat 49, 3000 Leuven, Belgium
}

Correspondence should be addressed to Frank Claessens; frank.claessens@med.kuleuven.be

Received 6 December 2013; Accepted 7 January 2014; Published 19 February 2014

Academic Editor: Giovanni Luca Gravina

Copyright (C) 2014 Thomas Van den Broeck et al. This is an open access article distributed under the Creative Commons Attribution License, which permits unrestricted use, distribution, and reproduction in any medium, provided the original work is properly cited.

Prostate cancer $(\mathrm{PCa})$ is a major health care problem because of its high prevalence, health-related costs, and mortality. Epidemiological studies have suggested an important role of genetics in PCa development. Because of this, an increasing number of single nucleotide polymorphisms (SNPs) had been suggested to be implicated in the development and progression of PCa. While individual SNPs are only moderately associated with PCa risk, in combination, they have a stronger, dose-dependent association, currently explaining $30 \%$ of PCa familial risk. This review aims to give a brief overview of studies in which the possible role of genetic variants was investigated in clinical settings. We will highlight the major research questions in the translation of SNP identification into clinical practice.

\section{Introduction}

Prostate cancer $(\mathrm{PCa})$ is a major health care problem because of its high prevalence, health-related costs, and mortality. Even though most patients have clinically localized and indolent tumors at diagnosis, worldwide, this disease still holds second place in the leading causes of cancer deaths [1]. Despite its prevalence, lethality, and socioeconomic burden, there are still many diagnostic and therapeutic challenges in the PCa field. This is mainly due to the lack of cancer- and/or patient-specific biomarkers, currently limiting patient-tailored diagnostics/therapeutics in PCa.

Age, race, and family history remain primary risk factors for the development of PCa. It has been shown that PCa is one of the most heritable cancers with epidemiological studies suggesting the role of genetics in PCa development $[2,3]$.

Due to the latter, there has been an increasing focus on the role of single nucleotide polymorphisms (SNPs) in the development and progression of $\mathrm{PCa}$ but also on their role in diagnostics and risk prediction. A SNP is a DNA sequence variation occurring when a single nucleotide $(A, T, C$, or $G)$ in the genome differs from the normally expected nucleotide.
These SNPs are known to underlie differences in our susceptibility to diseases. SNPs need to be determined only once and are easy to determine, making them interesting biomarkers. The rising interest in the role of SNPs in PCa development and progression is illustrated by the number of studies being published on SNPs in the PCa field.

In 2008, an extensive genome-wide association study (GWAS) compared SNPs between PCa cases and controls. Since then, numerous GWAS studies have been conducted [4-26]. While many SNPs were only moderately associated with PCa risk, in combination, they had a stronger, dosedependent (i.e., cumulative effect of number of SNPs) association. A total of 77 susceptibility loci are currently explaining approximately $30 \%$ of the familial risk [6]. With ongoing GWAS, we could expect that more genetic variants will be found, explaining more of the PCa familial risk. However, the question has been raised whether finding more PCa riskassociated SNPs will have added value over the currently known ones [27].

Many SNPs are connected to each other through "linkage disequilibrium," which is a nonrandom association of alleles at two or more loci, descendant from a single, ancestral 
chromosome. However, the SNPs detected through GWAS studies are mostly limited to "index SNPs," excluding other SNPs which are in linkage disequilibrium. Clearly, these index SNPs are not necessarily the SNPs causative for its associated phenotype (i.e., PCa risk, risk of progression, etc). Therefore, molecular analyses will be needed to identify the exact SNP within each linkage domain which is the causative SNP. SNPs that lie within an open reading frame can lead to changes in messenger RNA stability or translation efficiency, as well as changes in structure/activity of the encoded proteins. However, most SNPs are located outside of the genes and are suspected to affect gene expression levels and genome/chromatin organization. Therefore, it is interesting to determine the role of these SNPs in the clinical field. This review aims to give a selected overview of studies on the possible role of genetic variants in clinical practice. We will highlight diagnostic and therapeutic obstacles which are currently major issues in clinical practice.

\section{Evidence Synthesis}

2.1. Early Detection. To detect PCa in its early stages, currently, clinicians are limited to serum PSA level measurements as a marker, which lacks sensitivity and specificity. Therefore, PSA screening (defined as mass screening of asymptomatic men) has been heavily debated. Two prospective studies (The Prostate, Lung, Colorectal, and Ovarian (PLCO) Cancer Screening Trial and The European Randomized Study of Screening for Prostate Cancer (ERSPC)) have contributed greatly to this discussion. The PLCO study concluded that PCa-related mortality did not significantly differ between patients being screened or not [3]. The ERSPC study inferred that, based on PSA-based PCa detection, 1410 men would need to be screened and 48 additional cases of $\mathrm{PCa}$ would need to be treated to prevent one death from PCa, resulting in a high rate of over diagnosis [28].

In reaction to these recent results, the US Preventive Services Task Force has radically recommended against PSA-based screening [29]. However, they ignored the 50\% reduction in PCa-specific mortality since the introduction of PSA $[28,30]$. Moreover, without PSA testing, most men would only be diagnosed when they become symptomatic, when the disease is often too far advanced to cure. Therefore, the current EAU guidelines recommend opportunistic screening to the well-informed man [31]. Furthermore, there is an urgent need for the development of novel biomarkers.

2.1.1. Opportunistic Screening. Despite the EAU guidelines' recommendation on opportunistic PSA screening, the question remains which patients would benefit the most? Rephrased, we could ask ourselves which men are at an elevated risk of PCa? Since epidemiological studies have suggested a role of genetics in PCa development, it seems tempting to speculate that genetic variations could be of interest in predicting patients' risk of PCa in clinical practice [3]. Using this, clinicians could determine which patients would benefit from PSA screening or in which patient group they should have a low threshold of performing prostate biopsies.
Currently, these risk associations, detected by GWAS studies, are of limited clinical utility because the risk prediction is based on comparing groups of people. This allows for patient stratification into "risk groups," having an $\mathrm{x}$-fold greater $\mathrm{PCa}$ risk relative to the population average. However, for the clinician, it is of greater interest to be able to calculate a patient's absolute risk to develop PCa at a certain given point based on an individual's information.

Evaluating the efficiency of detecting PCa using a model based on family history, age, and genetic variation, Zheng et al. suggested comparable efficiency in detecting PCa when compared to the predictive power of PSA level cutoff of $4.1 \mathrm{ng} / \mathrm{mL}$ (see Table 1 for an overview of all SNPs cited in this paper) [32]. At first sight, this would seem irrelevant, since the efficiency of PSA testing itself is low. However, the economic burden of genetic testing could potentially be much lower, since this should only be determined once, whereas PSA levels fluctuate over time and often require multiple testing. The combined predictive performance of PSA plus genetic testing on PCa diagnostics unfortunately did not improve diagnostics once age, PSA level, and family history were known [32, 33].

Indeed, it was argued that SNPs are not good at discriminating cases from controls but might be of better use in identifying men at high risk of PCa [34]. In light of this, Xu et al. developed a prediction model of absolute risk for PCa at a specific age based on the sum of 14 SNPs and family history [35]. Using this model, one could identify a small subset (0.5-1\%) of individuals at very high risk ( $41 \%$ and $52 \%$ absolute risk in a US and Swedish population) of developing PCa between 55 and 74 years of age. Sun et al. studied the performance of three sets of PCa risk SNPs in predicting $\mathrm{PCa}$, showing that they are efficient at discriminating men who have a considerably elevated risk for PCa (a two- and threefold increase when compared to the population median risk) [36].

These risk predictions seem to have the highest impact in young patients with a family history of $\mathrm{PCa}[37,38]$. This seems logical, since one is born with a certain inheritable subset of SNPs, which do not change throughout one's life. Therefore, it could be expected that their effects would present in the earlier stages of life. Macinnis et al. developed a risk prediction algorithm for familial PCa, using 26 common variants, predicting the cumulative $\mathrm{PCa}$ risk depending on family history (from incidental PCa to highly burdened PCa families) and the number of SNPs (expressed in percentile of a SNP profile) [38].

Generalized, the future role of SNP genotyping in PCa screening seems to lie in detecting men at high risk of (aggressive) disease. Men with a higher likelihood of (aggressive) PCa may choose to begin PCa screening at an earlier age and/or more frequently. They may also pursue preventative measures, including diet/lifestyle intervention and chemoprevention.

It has been estimated that, when compared to age-specific screening, personalized screening would result in $16 \%$ fewer men being eligible for screening at a cost of $3 \%$ fewer screendetectable cases [39]. Importantly, SNPs can be determined with high accuracy, at low cost and at any age, which make 


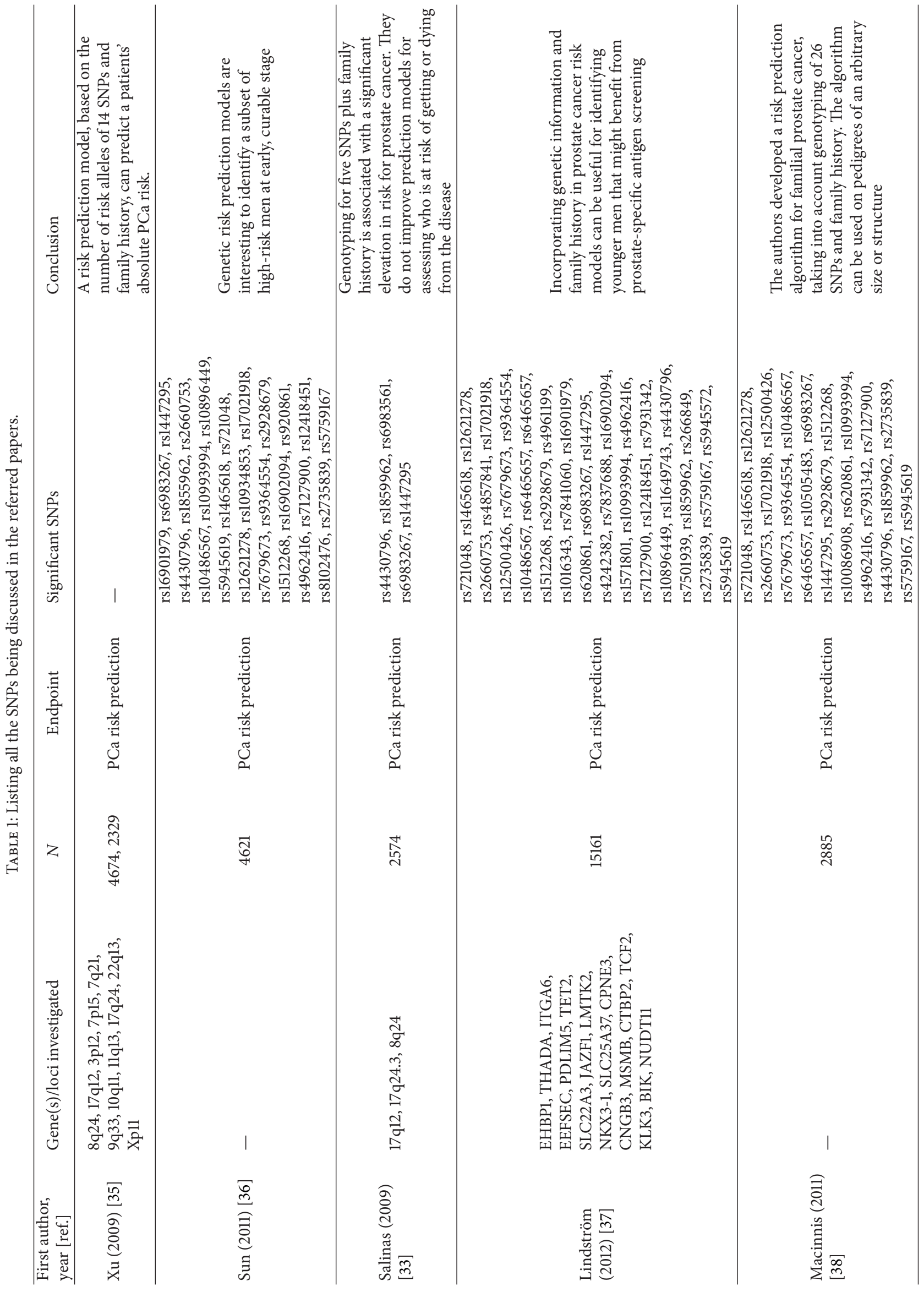




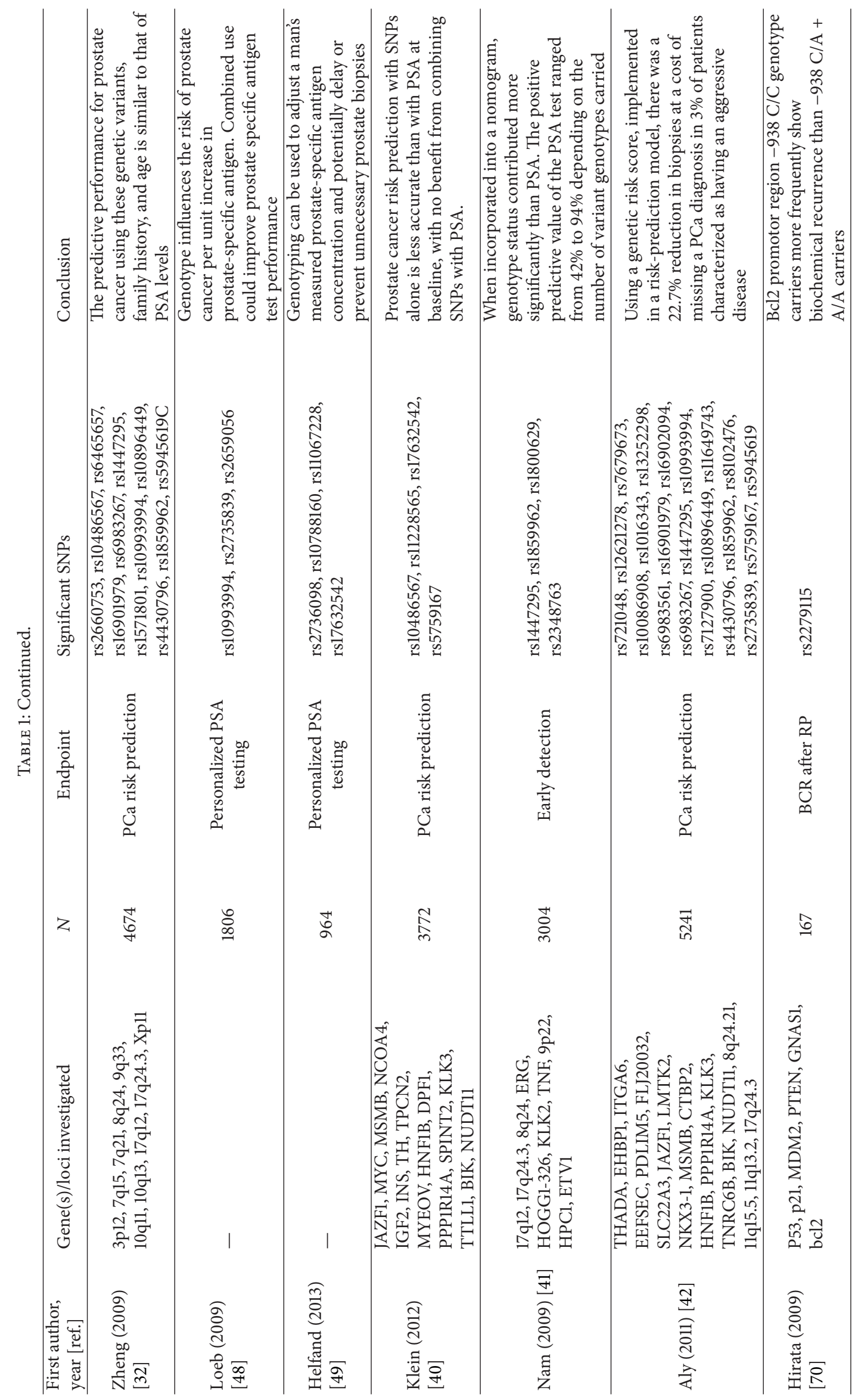




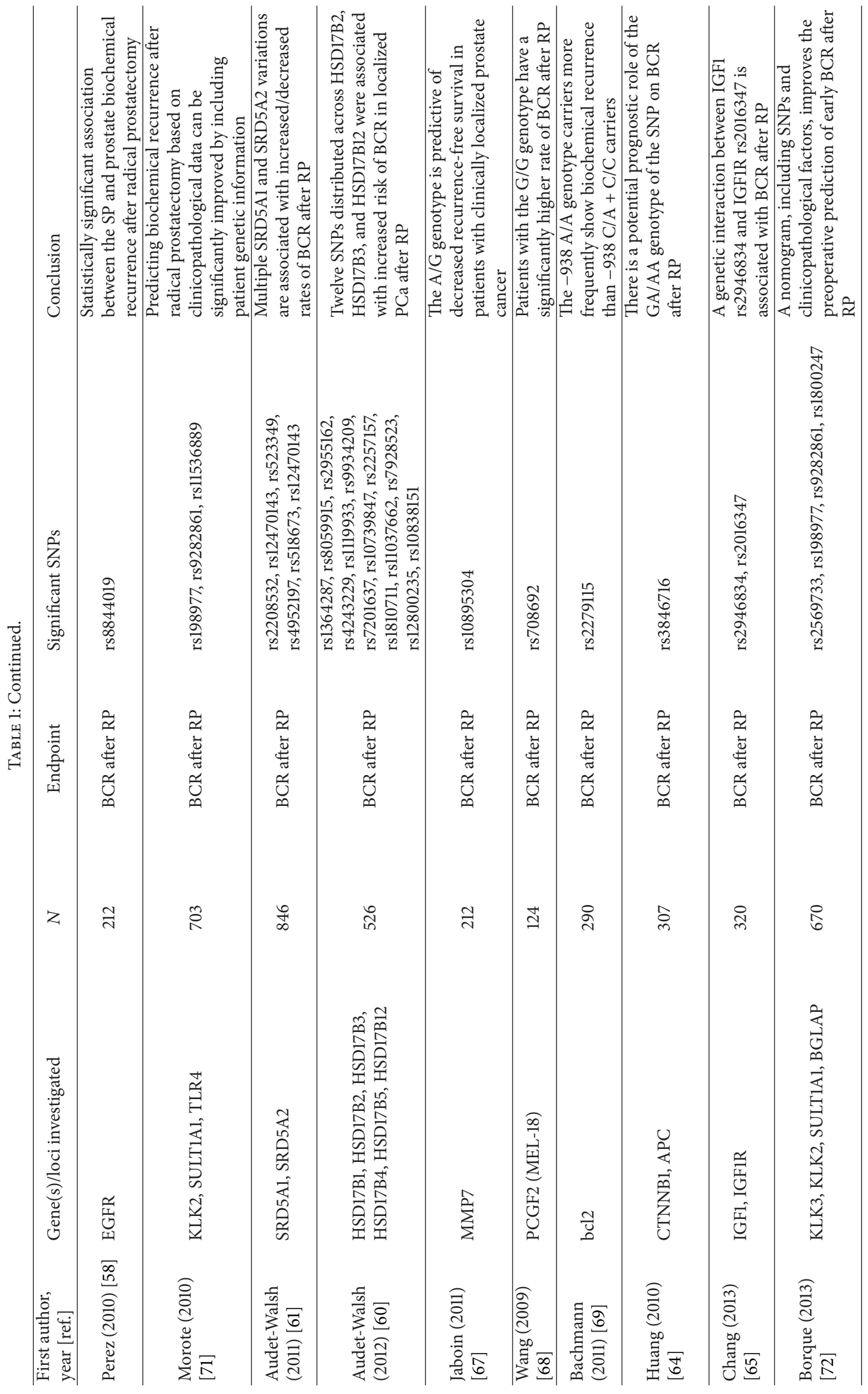




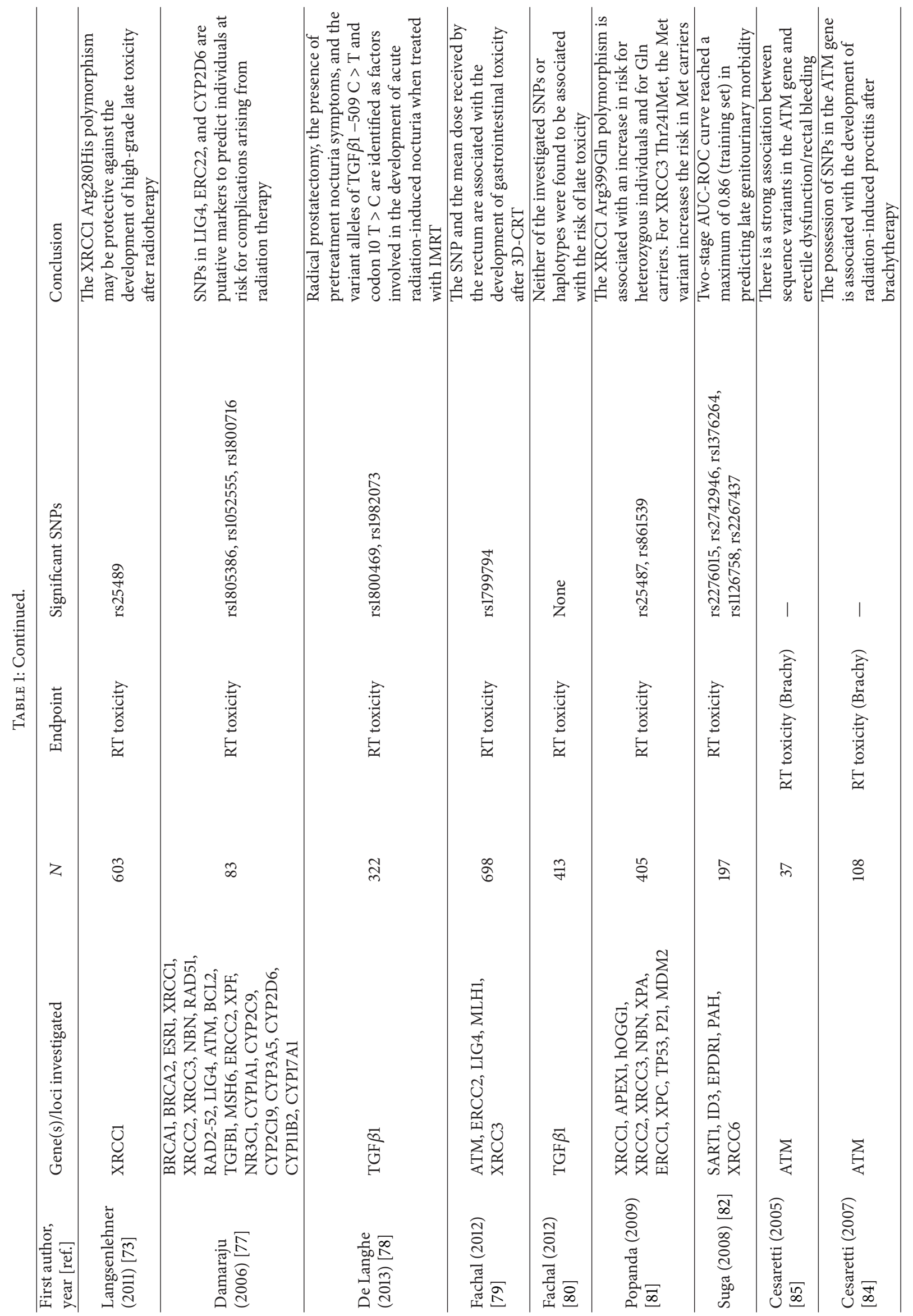




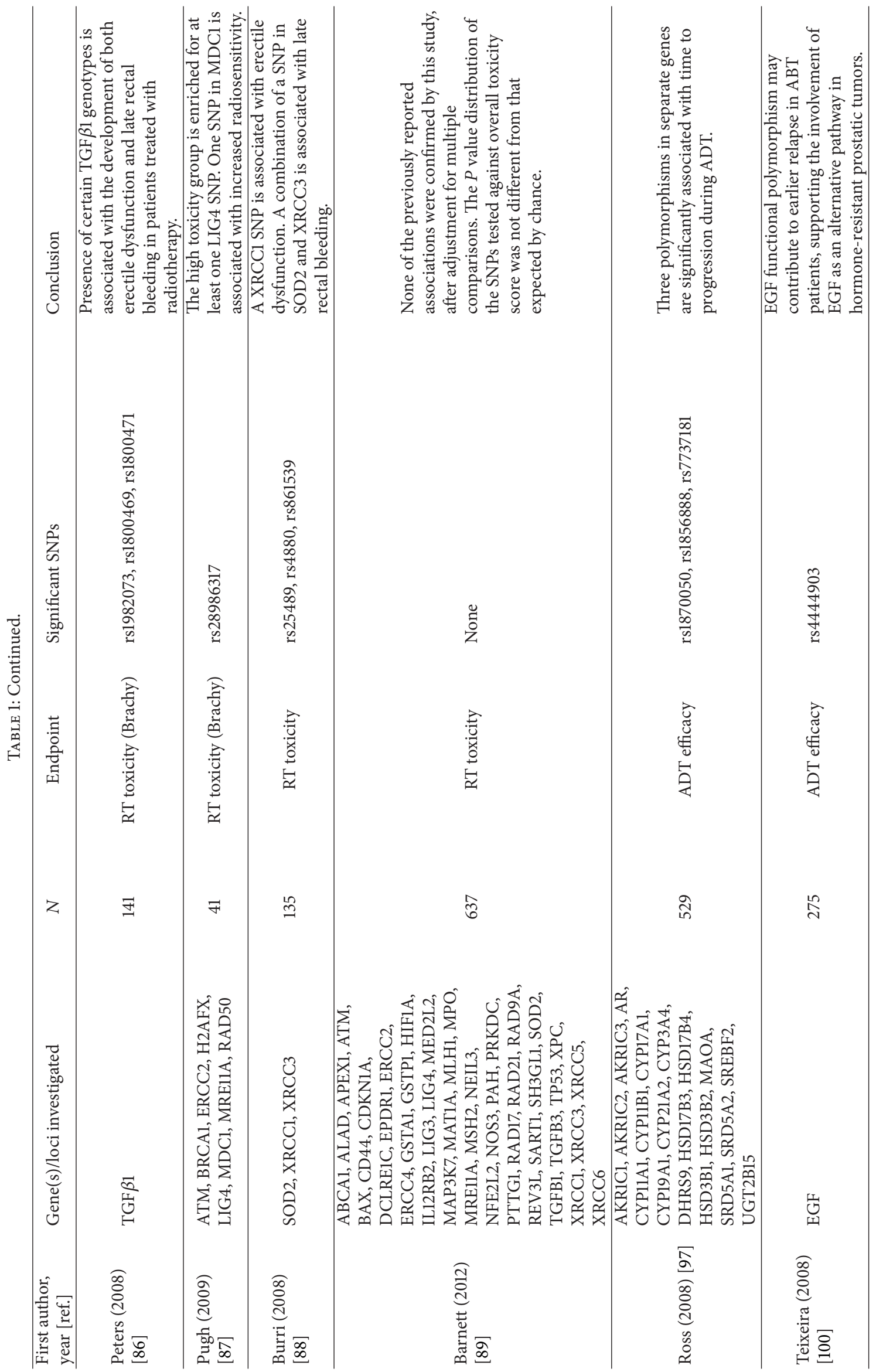




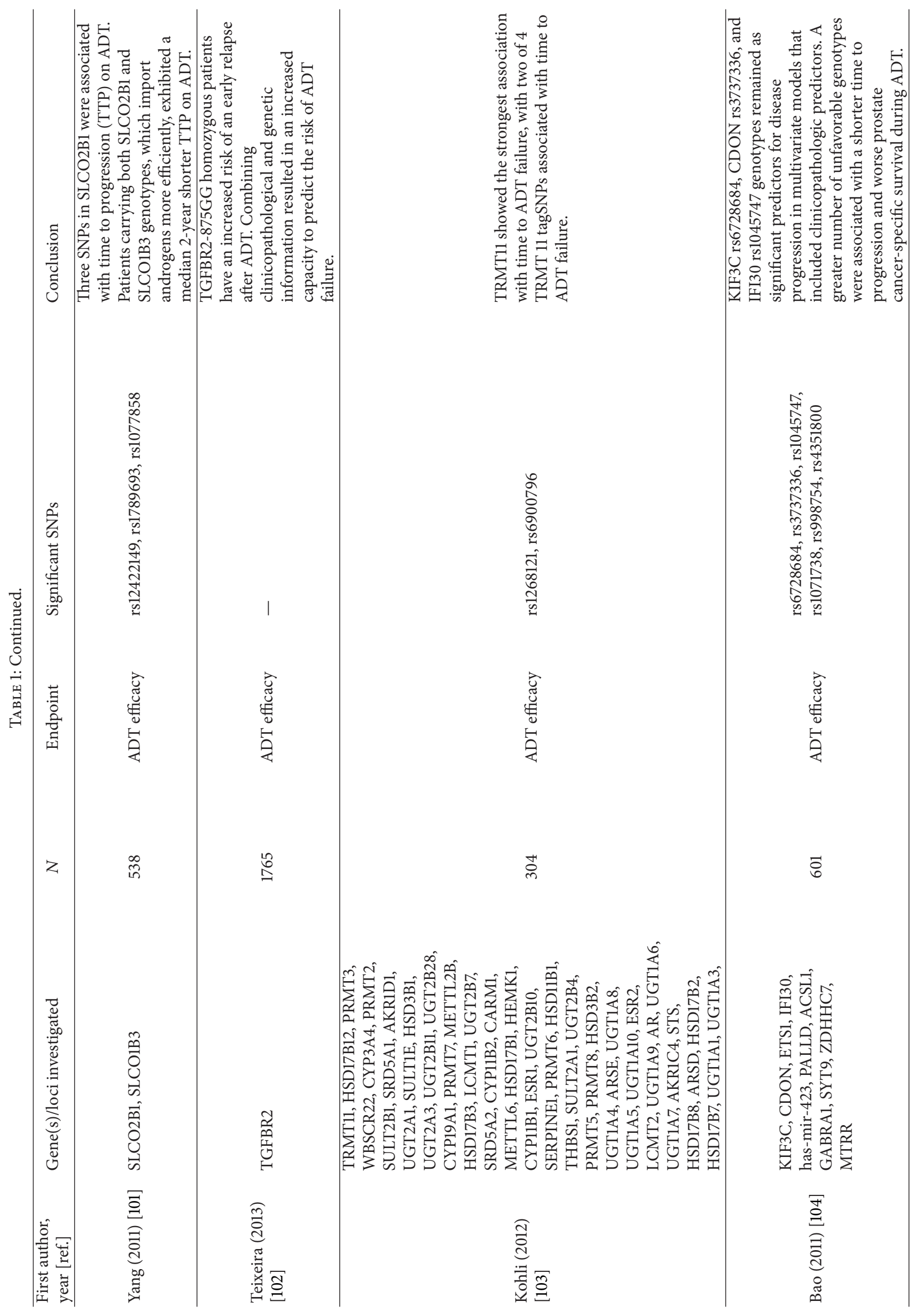




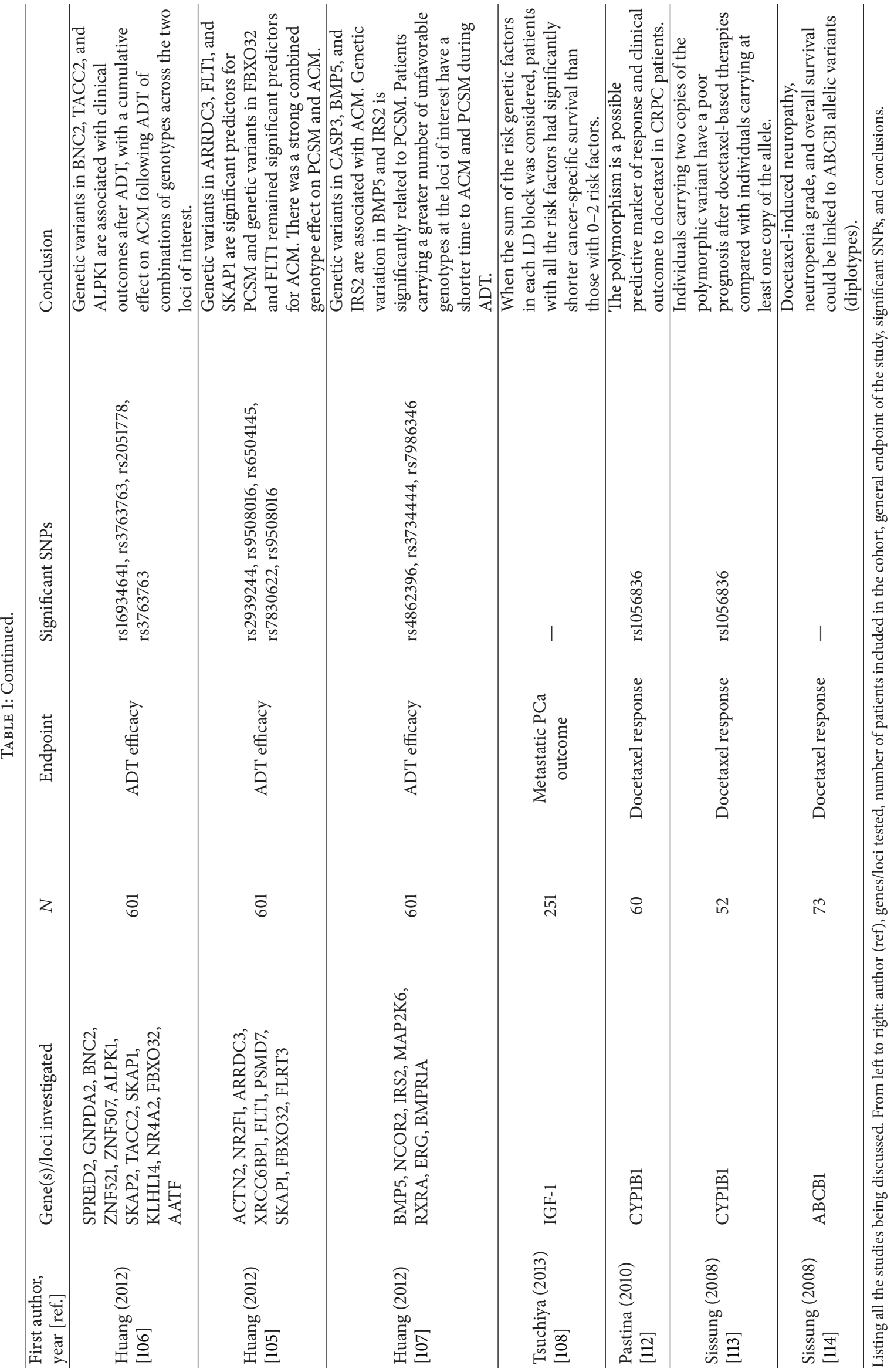


them attractive candidates to predict an individual's risk for PCa.

\subsubsection{SNPs in Interpreting (Novel) Biomarkers Levels. SNP} genotyping can result in a risk prediction, that is, estimating the likelihood of developing PCa. Currently, they have no role as true diagnostic markers. However, as Klein et al. have already stated, there might be other clinical uses for SNPs [40]. Hypothetically, they could be used in combination with PSA levels, increasing its predictive role [41, 42].

Furthermore, a profound knowledge on SNPs influencing novel biomarker levels would be of great interest, since this could play a crucial role in the interpretation of novel biomarkers. Fundamental research has already identified multiple SNPs playing a role in expression and/or function of hK2, $\beta$-MSP, TMPRSS2, and so forth [43-45], which could potentially have an important impact on their interpretation.

Recent evidence has suggested that PSA levels are subject to genetic variation as well, explaining $40-45 \%$ of variability in PSA levels in the general population [46]. This variability plays an important role in the low sensitivity and specificity of PSA testing, because of which there is no generalizable threshold at which men should undergo prostate biopsies.

Attempting to explain this variability, Gudmundsson et al. detected six loci associated with PSA levels, of which four had a combined relative effect on PSA level variation [47]. Other groups have validated this work. One group suggested that genetic correction could influence the risk of PCa per unit increased/decreased PSA [48]. Another group suggested that genetic correction could alter the number of men with an abnormal PSA (based on general biopsy thresholds), preventing up to 15 to $20 \%$ of prostatic biopsies, in this way reducing complications and costs and improving quality of life [49].

With the exponentially increasing interest and development of novel biomarkers in PCa, we should keep in mind that SNPs can clearly alter biomarker levels, which is crucial for correct interpretation. If these SNPs are not taken into account, we could foresee similar obstacles as we are seeing now with PSA testing.

2.2. Localized Disease. In treating localized PCa, defined as N0 M0 disease [31], there are multiple viable treatment options, each with its indications and contraindications. Based on clinical stage of the disease, age, and comorbidities, clinicians decide to enroll a patient in an active surveillance program or to start active treatment.

2.2.1. Active Surveillance. Active surveillance (defined as close monitoring of PSA levels combined with periodic imaging and repeat biopsies) is currently the golden standard for treating PCa with the lowest risk of cancer progression (cT1-2a, PSA $<10 \mathrm{ng} / \mathrm{mL}$, biopsy Gleason score $<6$ (at least 10 cores), $<2$ positive biopsies, minimal biopsy core involvement $(<50 \%$ cancer per biopsy)).

Although active surveillance has shown to be a viable option with excellent survival rates, reported conversion rates to active treatment range from $14 \%$ to $41 \%$. This delayed treatment, however, has no effect on survival rates [50].
Biomarker research in the "active surveillance group" should therefore mainly focus on detecting high-risk disease with high specificity, avoiding under- and overtreatment and making prevention and early intervention possible. This topic has already been discussed in the paragraph "early detection" (see Section 2.1).

2.2.2. Active Therapy. As it has become clear that, in patients with low-risk disease, active therapy can be delayed based on active surveillance protocols, it is clear as well that therapy is required in patients with intermediate and especially in patients with high-risk disease, as defined by the EAU guidelines.

In light of this, there are two large retrospective studies, determining 15-year mortality rates in men with PCa treated with noncurative intent. Firstly, Rider et al. found that PCa mortality is low in all men diagnosed with localized lowand intermediate-risk PCa. However, death rates are much higher in all men with localized high-risk disease with a $31 \%$ mortality rate [51]. Similar results were published by Akre et al., who have shown that in men with locally advanced PCa with a Gleason score of 7-10, where the PCa is managed with noncurative intent, $\mathrm{PCa}$-specific mortality rates range between 41 and $64 \%$ [52].

Reported incidence rates of high-risk PCa vary between $17 \%$ and $31 \%$, depending on how the disease was defined [53]. After primary treatment, patients with high-risk PCa have a higher risk of disease recurrence and progression, requiring multimodality treatment [31]. Currently, the two most established treatment options with curative intent are surgery and radiotherapy, each with its obstacles.

Radical Prostatectomy. In treating patients with intermediateand high-risk $\mathrm{PCa}$, radical prostatectomy can be curative for some patients, whilst others need a multidisciplinary approach. For clinicians, it is therefore of great interest to be able to define a patient's risk for persistence or relapse of disease before they start treatment. Based on these predictions, clinicians could decide to start with or withhold from adjuvant therapy, leading to a more personalized medicine.

At this moment, these predictions are based on nomograms, integrating preoperative clinical parameters, optimizing their prognostic value [54-56]. However, current clinical parameters still lack sufficient accuracy. Therefore, there is an enormous interest in developing novel biomarkers to optimize pretreatment risk stratification [57]. Regarding this, SNPs are especially interesting, since their use avoids PCa heterogeneity in a single specimen, limiting its pathological parameter accuracy $[58,59]$. Again, SNPs are not age-dependent and only need to be determined once, reducing patient burden and costs.

Multiple groups have identified SNPs that might be associated with higher rates of biochemical recurrence and/or shorter periods of biochemical-recurrence-free survival after radical prostatectomy. These polymorphisms are located in genes involved in steroid hormone biotransformation [6062], immune response [63], Wnt [64] and IGF1 [65] signaling pathways, and other genes associated with oncogenesis [6668]. However, conflicting results have already been reported 
by Bachman et al., who found that the AA genotype of the 938 BCL2 promotor polymorphism was an independent prognostic marker of relapse-free and overall survival in a Caucasian patient group [69]. This contrasted with results published by Hirata et al., who found the CC variant of the same promotor to be predictive for biochemical recurrence in a Japanese population [70].

Despite the numerous investigations on the role of SNPs in predicting biochemical recurrence after radical prostatectomy, only a few have been developed into a clinically applicable model, integrating clinicopathological data and genetic information [71, 72].

Radiotherapy. External beam radiotherapy (EBRT) is a second treatment option with curative intent for localized PCa. Currently, there is no solid evidence suggesting superiority of surgery or radiotherapy over the other. With the development of new techniques (IMRT, tomotherapy, and so forth) with escalating radiation doses, there has been an increase in patients being treated with EBRT for localized PCa.

Still, toxicities in neighboring normal tissues remain the major limiting factor for delivering optimal tumoricidal doses [73]. Normal-tissue radiation sensitivity mainly depends on treatment-related factors, which are defined as the total irradiation dose, the fractionated regimen, the total treatment time, and the irradiated volume. However, even for similar or identical treatment protocols, the extent of side effects shows substantial variation. This interindividual variation can be explained by patient-related factors [74].

Since patients with higher rates of side effects show no specific phenotypic trait, this suggests that subclinical genetic variations could explain these interindividual differences. Therefore, there has been an increasing interest in identifying the role of genetic variation and SNPs on treatment efficacy and normal-tissue radiosensitivity, termed "radiogenomics." Detecting these genetic variations could lead to the identification of subgroups of patients at risk for developing severe radiation-induced toxicity [75].

Based on a mechanistic understanding of the radiation pathogenesis, there has been a major interest in understanding the role of genetic variation in genes involved in DNA damage sensing (e.g., ATM), fibrogenesis (e.g., TGFB1), oxidative stress (e.g., SOD1), and major DNA repair pathways (e.g., XRCC1, XRCC3, ERCC2, and MLH1), showing conflicting results [73, 76-83]. Comparable studies have been performed in patients treated with brachytherapy [84-88].

These results are of great interest, since long-term genitourinary, sexual, and gastrointestinal quality of life are major issues guiding decision making with respect to curative management of PCa. In 2012, Barnett et al. aimed to prospectively validate SNPs which were at that time reported to be associated with radiation toxicity in a population of 637 patients treated with radical prostate radiotherapy. Despite previous evidence, none of the 92 investigated SNPs were associated with late normal tissue toxicity [89].

2.3. Metastatic Prostate Cancer. Since androgens have a pivotal role in the development of $\mathrm{PCa}$, the androgen receptor is the main target of systemic therapy for PCa. Androgen deprivation therapy (ADT) is the mainstay of treatment for patients with metastatic $\mathrm{PCa}$, of which chemical or surgical castration is the first-line treatment. Because of comparable efficacy between chemical and surgical castration, the latter generally has been replaced by chemical castration [90-92] .

2.3.1. Genetic Polymorphisms and ADT. Despite the efficiency of hormonal therapy in metastatic disease, eventually every patient will relapse, developing castration-resistant $\mathrm{PCa}$ (CRPC) [93]. Clinicians use well-studied clinicopathologic parameters (PSA kinetics and Gleason Score and so forth) to predict which patients will not respond well to ADT and which patients have poor prognosis [94-96]. Still, these parameters are insufficient for prediction, which is suggested by the recommendation of the EAU guidelines that LHRH agonists should be continued, even in a castration-resistant state [31]. In light of this, genetic markers could be an attractive way to improve risk stratification, predicting which patients will respond less to ADT and have poor prognosis, warranting closer follow-up.

Ross et al. underlined the importance of pharmacogenomics on an individuals' response to ADT [97]. They associated three SNPs located in/close to CYP19A1 (encodes for aromatase, a key enzyme that converts testosterone to estrogen in men), HSD3B1 (associated with PCa susceptibility) [98], and HSD17B4 (overexpression associated with higher Gleason grade) [99]. These SNPs were significantly associated with time to progression, having an additive effect when combined.

Later on, SNPs in multiple other loci have shown to be correlated with earlier relapse in patients treated with ADT. Currently known loci of interest are situated in the EGF gene [100] (known to activate several prooncogenic signaling pathways), in two androgen transporter genes (SLCO2B1 and SLCO1B3) [101] and in the TGF $\beta$ R2 gene. The latter codes for a receptor involved in TGF $\beta$ signaling pathway, playing a role in carcinogenesis and tumor progression [102]. In contrast to these, some SNPs associated with time to progression under ADT, are located in genes of which the function is still unknown [103].

Moreover, a Taiwanese group developed a DNA library of 601 men with "advanced prostate cancer" treated with ADT, in which they detected 5 SNPs that were correlated with progression and 14 SNPs correlated with $\mathrm{PCa}$-specific mortality under ADT [104-107]. Bao et al. detected four SNPs within miRNAs and miRNA target sites that were associated with disease progression [104]. Furthermore, Huang et al. systematically investigated 55 and 49 common SNPs in androgen- and estrogen-receptor-binding sites, after which they withheld one SNP (located in BNC2) which is correlated with progression and 5 SNPs (located in ARRDC3, FLT1, SKAP1, BNC2, and TACC2), which are correlated with PCaspecific mortality $[105,106]$. Finally, Huang et al. associated a SNP in the BMP5 and IRS2 gene with survival [107]. The latter encodes a member of a family of intracellular signaling adaptor proteins that coordinate numerous biologically key extracellular signals within the cell, including insulin-like growth factor 1 (IGF1), of which the genotype seems to be correlated with survival in metastatic PCa as well [108]. This 
only shows how complex and interwoven the clinical effects of genetic variation can be.

Although these results are very interesting, it should be noted that the investigated patient group is very heterogeneous. In this population with "advanced PCa," tumor characteristics show that $33 \%$ of patients have a Gleason score ranging from 2 to 6 and $31.7 \%$ of patients have T1/T2 tumors. Furthermore, the setting in which ADT was given was very heterogeneous, ranging from ADT in neoadjuvant setting to ADT for biochemical failure after radical prostatectomy. This heterogeneity limits the interpretation of genetic variation in clinical situations such as these.

Hypothetically, there are multiple potential clinical benefits of SNP genotyping with respect to ADT therapy. Firstly, it could play a prognostic role in identifying patients at high risk of therapeutic failure. This could help identify a subset of patients who may benefit from a more aggressive initial treatment strategy than ADT alone, including combinations with novel drugs [103]. Secondly, polymorphisms with functional implications on enzyme activity could be targeted with novel therapeutics, improving ADT efficacy [97].

2.3.2. Genetic Polymorphisms in the Castrate-Resistant PCa. In the castrate-resistant setting, taxane-based chemotherapy (docetaxel) has been the only treatment option for many years, based on two multicenter phase III randomized clinical trials, showing a moderate increase in overall survival [109, 110]. Over the last few years, numerous novel therapeutics have been developed in this setting. However, equally many questions regarding the optimal treatment regimen remain. Clinical evidence showing superiority to one treatment option over the other is severely lacking, keeping clinicians in the dark on the optimal treatment.

When treatment with docetaxel is started, there is a high variability in the clinical response [111]. Therefore, it would be of great interest to be able to predict this response rate before treatment is started. Based on this, the clinician could decide to withhold from docetaxel as first-line treatment and choose another treatment option.

Genetic variation in the CYP1B1 gene has shown to predict outcome in CRPC patients receiving first-line docetaxel. Pastina et al. showed that patients, carrying the CYP1B1 4326 GG genotype, had significantly shorter overall survival rates when compared to patients carrying CYP1B1 4326 GC or CC. Even after correcting for other risk factors (e.g., demographics, pathological, and biochemical characteristics), this genotype remained an independent predictive parameter of risk of death. This suggests that the 4326GG genotype might be a good pharmacogenetic marker of lower prevalence of response to docetaxel in CRPC patients [112]. It is suggested that its role probably lies in the effect it has on the levels of 4-hydroxyestradiol, which is the major CYP1B1 metabolite. The metabolite interferes with the chemotherapy-induced microtubule stabilization and structurally alters docetaxel [113]. Another gene of interest is the ABCB1 gene, which is responsible for a large portion of the systemic efflux of docetaxel. Within this gene, a combination of ABCB1 1236, 2677 , and 3435 genotypes seems to be correlated with survival in CRPC patients receiving docetaxel and time to developing neuropathy in patients receiving a combination of docetaxel and thalidomide. The latter is probably due to cumulative effects on toxicity [114].

With the growing number of new treatment options, these results are very interesting for future clinical use. Using these, clinicians could individualize treatment regimens based on a patient's genotype. Similarly, the role of SNPs in predicting therapeutic efficacy of novel therapeutic agents like abiraterone and enzalutamide awaits to be assessed.

\section{Conclusions}

Since the definition of the human genome, the basis for genetic variations that can lead to individual risks for diseases has become more and more clear. Genome-wide association studies (GWAS) have defined groups of SNPs which partially predict increased risk for PCa. As suggested in this review, SNPs have a great potential in predicting patients' risk for PCa and/or therapy response, which could have an important impact in every day clinic.

Although many authors have suggested that genetic information can improve risk prediction and therefore be useful in clinical practice, there are several studies showing contradicting results, limiting their current clinical use. These contradicting results could be explained by multiple reasons. First, studies performed on small, heterogeneous populations might result in high rates of false positive and negative data. Secondly, most conducted studies are based on SNPs which have been correlated with PCa in GWAS studies. Since PCa phenotypes are probably determined by a spectrum of genetic variation (ranging from highly penetrant to low penetrant variations), with possible interdependencies of SNPs, GWAS studies are probably not sufficient to develop a full understanding of these variations in PCa.

Throughout this review, it has become clear that some challenges still remain for translational research on the role of SNPs in PCa. Firstly, clinical studies on SNPs should be performed in well-powered studies, which could give more conclusive results. Secondly, the important challenge for further basic research is to identify the causative SNPs within each linkage equilibrium. Hopefully, these SNPs will not only function as predictors but also give clues to important pathways in PCa development, which could be therapeutic targets.

It will only be after the enrichment of GWAS data by detailed SNP mapping and functional SNP testing that the most relevant SNPs can be analyzed in clinical research. In the future, we expect them to become critical to interpret individualized PCa risk, interindividual biomarker variation, and therapeutic response.

\section{Conflict of Interests}

The authors declare that there is no conflict of interests regarding the publication of this paper.

\section{Acknowledgments}

The authors gratefully acknowledge financial support from the company Ravago Distribution Center NV (LUOR fonds). 
This study was further financially supported by the Fundacion Federico, Grant OT/09/035 from the Katholieke Universiteit Leuven, and Grant nos. G.0684.12 and G.0830.13 of the Fund for Scientific Research Flanders, Belgium (FWOVlaanderen). Steven Joniau is holder of a grant from the Klinisch Onderzoeksfonds (KOF) from UZ Leuven.

\section{References}

[1] R. Siegel, D. Naishadham, and A. Jemal, "Cancer statistics 2013," CA: A Cancer Journal for Clinicians, vol. 63, no. 1, pp. 11-30, 2013.

[2] D. J. Schaid, "The complex genetic epidemiology of prostate cancer," Human Molecular Genetics, vol. 13, no. 1, pp. R103-R121, 2004.

[3] P. Lichtenstein, N. V. Holm, P. K. Verkasalo et al., "Environmental and heritable factors in the causation of cancer: analyses of cohorts of twins from Sweden, Denmark, and Finland," The New England Journal of Medicine, vol. 343, no. 2, pp. 78-85, 2000.

[4] R. Takata, S. Akamatsu, M. Kubo et al., "Genome-wide association study identifies five new susceptibility loci for prostate cancer in the Japanese population," Nature Genetics, vol. 42, no. 9, pp. 751-754, 2010.

[5] J. Xu, Z. Mo, D. Ye et al., "Genome-wide association study in Chinese men identifies two new prostate cancer risk loci at 9q31. 2 and 19q13. 4.", Nature Genetics, vol. 44, no. 11, pp. 1231-1235, 2012.

[6] R. A. Eeles, A. A. Al Olama, S. Benlloch et al., "Identification of 23 new prostate cancer susceptibility loci using the iCOGS custom genotyping array," Nature Genetics, vol. 45, no. 4, pp. 385-391, 2013.

[7] J. Gudmundsson, P. Sulem, A. Manolescu et al., "Genomewide association study identifies a second prostate cancer susceptibility variant at 8q24," Nature Genetics, vol. 39, no. 5, pp. 631637, 2007.

[8] J. Gudmundsson, P. Sulem, V. Steinthorsdottir et al., "Two variants on chromosome 17 confer prostate cancer risk, and the one in TCF2 protects against type 2 diabetes," Nature Genetics, vol. 39, no. 8, pp. 977-983, 2007.

[9] M. Yeager, N. Orr, R. B. Hayes et al., "Genome-wide association study of prostate cancer identifies a second risk locus at 8q24," Nature Genetics, vol. 39, no. 5, pp. 645-649, 2007.

[10] J. Sun, S. L. Zheng, F. Wiklund et al., "Sequence variants at 22q13 are associated with prostate cancer risk," Cancer Research, vol. 69, no. 1, pp. 10-15, 2009.

[11] R. Eeles, Z. Kote-Jarai, and A. Al Olama, "Identification of seven new prostate cancer susceptibility loci through a genome-wide association study," Nature Genetics, vol. 41, no. 10, pp. 1116-1121, 2009.

[12] C. A. Haiman, G. K. Chen, W. J. Blot et al., "Genome-wide association study of prostate cancer in men of African ancestry identifies a susceptibility locus at 17q21," Nature Genetics, vol. 43, no. 6, pp. 570-573, 2011.

[13] J. Gudmundsson, P. Sulem, and T. Rafnar, "Common sequence variants on 2 p15 and Xp11. 22 confer susceptibility to prostate cancer," Nature Genetics, vol. 40, no. 3, pp. 281-283, 2008.

[14] J. Gudmundsson, P. Sulem, D. F. Gudbjartsson et al., "Genomewide association and replication studies identify four variants associated with prostate cancer susceptibility," Nature Genetics, vol. 41, no. 10, pp. 1122-1126, 2009.
[15] Z. Kote-Jarai, A. Al Olama, and G. Giles, "Seven prostate cancer susceptibility loci identified by a multi-stage genomewide association study," Nature Genetics, vol. 43, no. 8, pp. 785791, 2011.

[16] J. M. Murabito, C. L. Rosenberg, D. Finger et al., "A genomewide association study of breast and prostate cancer in the NHLBI's Framingham Heart Study,' BMC Medical Genetics, vol. 8, supplement 1, article S6, 2007.

[17] I. Cheng, G. K. Chen, H. Nakagawa et al., "Evaluating genetic risk for prostate cancer among Japanese and Latinos," Cancer Epidemiology, Biomarkers \& Prevention, vol. 21, no. 11, pp. 20482058, 2012.

[18] L. M. FitzGerald, E. M. Kwon, M. P. Conomos et al., "Genomewide association study identifies a genetic variant associated with risk for more aggressive prostate cancer," Cancer Epidemiology Biomarkers and Prevention, vol. 20, no. 6, pp. 1196-1203, 2011.

[19] R. K. Nam, W. Zhang, K. Siminovitch et al., "New variants at $10 \mathrm{q} 26$ and $15 \mathrm{q} 21$ are associated with aggressive prostate cancer in a genome-wide association study from a prostate biopsy screening cohort," Cancer Biology and Therapy, vol. 12, no. 11, pp. 997-1004, 2011.

[20] F. R. Schumacher, S. I. Berndt, A. Siddiq et al., "Genome-wide association study identifies new prostate cancer susceptibility loci," Human Molecular Genetics, vol. 20, no. 19, pp. 3867-3875, 2011.

[21] J. Shan, K. Al-Rumaihi, D. Rabah et al., "Genome scan study of prostate cancer in Arabs: identification of three genomic regions with multiple prostate cancer susceptibility loci in Tunisians," Journal of Translational Medicine, vol. 11, article 121, 2013.

[22] S. Tao, J. Feng, T. Webster et al., "Genome-wide two-locus epistasis scans in prostate cancer using two European populations," Human Genetics, vol. 131, no. 7, pp. 1225-1234, 2012.

[23] A. Amin Al Olama, Z. Kote-Jarai, F. R. Schumacher et al., "A meta-analysis of genome-wide association studies to identify prostate cancer susceptibility loci associated with aggressive and non-aggressive disease," Human Molecular Genetics, vol. 22, no. 2, pp. 408-415, 2013.

[24] D. Duggan, S. L. Zheng, M. Knowlton et al., "Two genomewide association studies of aggressive prostate cancer implicate putative prostate tumor suppressor gene DAB2IP," Journal of the National Cancer Institute, vol. 99, no. 24, pp. 1836-1844, 2007.

[25] R. A. Eeles, Z. Kote-Jarai, G. G. Giles et al., "Multiple newly identified loci associated with prostate cancer susceptibility," Nature Genetics, vol. 40, no. 3, pp. 316-321, 2008.

[26] G. Thomas, K. B. Jacobs, M. Yeager et al., "Multiple loci identified in a genome-wide association study of prostate cancer," Nature Genetics, vol. 40, no. 3, pp. 310-315, 2008.

[27] S. Ren, J. Xu, T. Zhou et al., "Plateau effect of prostate cancer risk-associated SNPs in discriminating prostate biopsy outcomes," Prostate, vol. 73, no. 16, pp. 1824-1835, 2013.

[28] F. H. Schröder, J. Hugosson, M. J. Roobol et al., "Screening and prostate-cancer mortality in a randomized european study," The New England Journal of Medicine, vol. 360, no. 13, pp. 1320-1328, 2009.

[29] V. A. Moyer, "Screening for prostate cancer: U.S. Preventive Services Task Force recommendation statement," Annals of Internal Medicine, vol. 157, no. 2, pp. 120-134, 2012.

[30] P. C. Walsh, "Re: screening for prostate cancer: U.S. Preventive Services Task Force recommendation statement," Journal of Urology, vol. 188, no. 4, p. 1181, 2012. 
[31] A. Heidenreich, G. Aus, M. Bolla, and S. Joniau, "EAU guidelines on prostate cancer," European Urology, vol. 53, pp. 31-45, 2008.

[32] S. L. Zheng, J. Sun, F. Wiklund et al., "Genetic variants and family history predict prostate cancer similar to prostate-specific antigen," Clinical Cancer Research, vol. 15, no. 3, pp. 1105-1111, 2009.

[33] C. A. Salinas, J. S. Koopmeiners, E. M. Kwon et al., "Clinical utility of five genetic variants for predicting prostate cancer risk and mortality," Prostate, vol. 69, no. 4, pp. 363-372, 2009.

[34] M. S. Pepe, H. Janes, G. Longton, W. Leisenring, and P. Newcomb, "Limitations of the odds ratio in gauging the performance of a diagnostic, prognostic, or screening marker," American Journal of Epidemiology, vol. 159, no. 9, pp. 882-890, 2004.

[35] J. Xu, J. Sun, A. K. Kader et al., "Estimation of absolute risk for prostate cancer using genetic markers and family history," Prostate, vol. 69, no. 14, pp. 1565-1572, 2009.

[36] J. Sun, A. K. Kader, F.-C. Hsu et al., "Inherited genetic markers discovered to date are able to identify a significant number of men at considerably elevated risk for prostate cancer," Prostate, vol. 71, no. 4, pp. 421-430, 2011.

[37] S. Lindström, F. R. Schumacher, D. Cox et al., "Common genetic variants in prostate cancer risk prediction-results from the NCI breast and prostate cancer cohort consortium (BPC3)," Cancer Epidemiology Biomarkers and Prevention, vol. 21, no. 3, pp. 437-444, 2012.

[38] R. J. Macinnis, A. C. Antoniou, R. A. Eeles et al., "A risk prediction algorithm based on family history and common genetic variants: application to prostate cancer with potential clinical impact," Genetic Epidemiology, vol. 35, no. 6, pp. 549556, 2011.

[39] N. Pashayan, S. W. Duffy, S. Chowdhury et al., "Polygenic susceptibility to prostate and breast cancer: implications for personalised screening," British Journal of Cancer, vol. 104, no. 10, pp. 1656-1663, 2011.

[40] R. J. Klein, C. Hallden, A. Gupta et al., "Evaluation of multiple risk-associated single nucleotide polymorphisms versus prostate-specific antigen at baseline to predict prostate cancer in unscreened men," European Urology, vol. 61, no. 3, pp. 471477, 2012.

[41] R. K. Nam, W. W. Zhang, J. Trachtenberg et al., "Utility of incorporating genetic variants for the early detection of prostate cancer," Clinical Cancer Research, vol. 15, no. 5, pp. 1787-1793, 2009.

[42] M. Aly, F. Wiklund, J. Xu et al., "Polygenic risk score improves prostate cancer risk prediction: results from the Stockholm-1 cohort study," European Urology, vol. 60, no. 1, pp. 21-28, 2011.

[43] X. Xu, C. Valtonen-André, C. Sävblom, C. Halldén, H. Lilja, and R. J. Klein, "Polymorphisms at the microseminoprotein- $\beta$ locus associated with physiologic variation in $\beta$-microseminoprotein and prostate-specific antigen levels," Cancer Epidemiology Biomarkers and Prevention, vol. 19, no. 8, pp. 2035-2042, 2010.

[44] R. J. Klein, C. Halldén, A. M. Cronin et al., "Blood biomarker levels to aid discovery of cancer-related single-nucleotide polymorphisms: Kallikreins and prostate cancer," Cancer Prevention Research, vol. 3, no. 5, pp. 611-619, 2010.

[45] L. Clinckemalie, L. Spans, V. Dubois et al., "Androgen regulation of the TMPRSS2 gene and the effect of a SNP in an Androgen Response Element," Molecular Endocrinology, vol. 27, no. 12, pp. 2028-2040, 2013.

[46] A. Bansal, D. K. Murray, J. T. Wu, R. A. Stephenson, R. G. Middleton, and A. W. Meikle, "Heritability of prostate-specific antigen and relationship with zonal prostate volumes in aging twins," Journal of Clinical Endocrinology and Metabolism, vol. 85, no. 3, pp. 1272-1276, 2000.

[47] J. Gudmundsson, S. Besenbacher, P. Sulem et al., "Genetic correction of PSA values using sequence variants associated with PSA levels," Science Translational Medicine, vol. 2, no. 62, Article ID 62ra92, 2010.

[48] S. Loeb, H. B. Carter, P. C. Walsh et al., "Single nucleotide polymorphisms and the likelihood of prostate cancer at a given prostate specific antigen level," Journal of Urology, vol. 182, no. 1, pp. 101-105, 2009.

[49] B. T. Helfand, S. Loeb, Q. Hu et al., "Personalized prostate specific antigen testing using genetic variants may reduce unnecessary prostate biopsies," Journal of Urology, vol. 189, no. 5, pp. 1697-1701, 2013.

[50] M. R. Cooperberg, P. R. Carroll, and L. Klotz, "Active surveillance for prostate cancer: progress and promise," Journal of Clinical Oncology, vol. 29, no. 27, pp. 3669-3676, 2011.

[51] J. R. Rider, F. Sandin, O. Andrén, P. Wiklund, J. Hugosson, and P. Stattin, "Long-term outcomes among noncuratively treated men according to prostate cancer risk category in a nationwide, population-based study," European Urology, vol. 63, no. 1, pp. 88-96, 2013.

[52] O. Akre, H. Garmo, J. Adolfsson, M. Lambe, O. Bratt, and P. Stattin, "Mortality among men with locally advanced prostate cancer managed with noncurative intent: a nationwide study in PCBaSe Sweden," European Urology, vol. 60, no. 3, pp. 554-563, 2011.

[53] M. R. Cooperberg, J. Cowan, J. M. Broering, and P. R. Carroll, "High-risk prostate cancer in the United States, 1990-2007," World Journal of Urology, vol. 26, no. 3, pp. 211-218, 2008.

[54] A. Briganti, S. Joniau, P. Gontero et al., "Identifying the best candidate for radical prostatectomy among patients with highrisk prostate cancer," European Urology, vol. 61, no. 3, pp. 584$592,2012$.

[55] S. Joniau, C.-Y. Hsu, E. Lerut et al., "A pretreatment table for the prediction of final histopathology after radical prostatectomy in clinical unilateral T3a prostate cancer," European Urology, vol. 51, no. 2, pp. 388-394, 2007.

[56] M. Spahn, S. Joniau, P. Gontero et al., "Outcome predictors of radical prostatectomy in patients with prostate-specific antigen greater than $20 \mathrm{ng} / \mathrm{ml}$ : a European multi-institutional study of 712 patients," European Urology, vol. 58, no. 1, pp. 1-7, 2010.

[57] R. S. Svatek, C. Jeldres, P. I. Karakiewicz et al., "Pre-treatment biomarker levels improve the accuracy of post-prostatectomy nomogram for prediction of biochemical recurrence," Prostate, vol. 69, no. 8, pp. 886-894, 2009.

[58] C. A. Perez, H. Chen, Y. Shyr et al., "The EGFR polymorphism rs884419 is associated with freedom from recurrence in patients with resected prostate cancer," Journal of Urology, vol. 183, no. 5, pp. 2062-2069, 2010.

[59] S.-P. Huang, L.-C. Huang, W.-C. Ting et al., "Prognostic significance of prostate cancer susceptibility variants on prostatespecific antigen recurrence after radical prostatectomy," Cancer Epidemiology Biomarkers and Prevention, vol. 18, no. 11, pp. 3068-3074, 2009.

[60] É. Audet-Walsh, J. Bellemare, L. Lacombe et al., "The impact of germline genetic variations in hydroxysteroid (17-Beta) dehydrogenases on prostate cancer outcomes after prostatectomy," European Urology, vol. 62, no. 1, pp. 88-96, 2012. 
[61] E. Audet-Walsh, J. Bellemare, G. Nadeau et al., "SRD5A polymorphisms and biochemical failure after radical prostatectomy," European Urology, vol. 60, no. 6, pp. 1226-1234, 2011.

[62] J. Cotignola, D. B. Leonardi, A. Shahabi et al., "Glutathione-Stransferase (GST) polymorphisms are associated with relapse after radical prostatectomy," Prostate Cancer and Prostatic Diseases, vol. 16, no. 1, pp. 28-34, 2013.

[63] P. J. Dluzniewski, M.-H. Wang, S. L. Zheng et al., "Variation in IL10 and other genes involved in the immune response and in oxidation and prostate cancer recurrence," Cancer Epidemiology, Biomarkers \& Prevention, vol. 21, no. 10, pp. 17741782, 2012.

[64] S.-P. Huang, W.-C. Ting, L.-M. Chen et al., "Association analysis of Wnt pathway genes on prostate-specific antigen recurrence after radical prostatectomy," Annals of Surgical Oncology, vol. 17, no. 1, pp. 312-322, 2010.

[65] C.-F. Chang, J.-B. Pao, C.-C. Yu et al., "Common variants in IGF1 pathway genes and clinical outcomes after radical prostatectomy," Annals of Surgical Oncology, vol. 20, no. 7, pp. 2446-2452, 2013.

[66] S.-P. Huang, Y.-H. Lan, T.-L. Lu et al., "Clinical significance of runt-related transcription factor 1 polymorphism in prostate cancer," BJU International, vol. 107, no. 3, pp. 486-492, 2011.

[67] J. J. Jaboin, M. Hwang, Z. Lopater et al., "The matrix metalloproteinase-7 polymorphism RS10895304 is associated with increased recurrence risk in patients with clinically localized prostate cancer," International Journal of Radiation Oncology Biology Physics, vol. 79, no. 5, pp. 1330-1335, 2011.

[68] W. Wang, T. Yuasa, N. Tsuchiya et al., "The novel tumorsuppressor Mel-18 in prostate cancer: its functional polymorphism, expression and clinical significance," International Journal of Cancer, vol. 125, no. 12, pp. 2836-2843, 2009.

[69] H. S. Bachmann, L. C. Heukamp, K. J. Schmitz et al., "Regulatory BCL2 promoter polymorphism $(-938 \mathrm{C}>\mathrm{A})$ is associated with adverse outcome in patients with prostate carcinoma," International Journal of Cancer, vol. 129, no. 10, pp. 2390-2399, 2011.

[70] H. Hirata, Y. Hinoda, N. Kikuno et al., "Bcl2 -938C/A polymorphism carries increased risk of biochemical recurrence after radical prostatectomy," Journal of Urology, vol. 181, no. 4, pp. 1907-1912, 2009.

[71] J. Morote, J. Del Amo, A. Borque et al., "Improved prediction of biochemical recurrence after radical prostatectomy by genetic polymorphisms," Journal of Urology, vol. 184, no. 2, pp. 506-511, 2010.

[72] Á. Borque, J. del Amo, L. M. Esteban et al., "Genetic predisposition to early recurrence in clinically localized prostate cancer," BJU International, vol. 111, no. 4, pp. 549-558, 2013.

[73] T. Langsenlehner, W. Renner, A. Gerger et al., "Association between single nucleotide polymorphisms in the gene for $\mathrm{XRCC} 1$ and radiation-induced late toxicity in prostate cancer patients," Radiotherapy and Oncology, vol. 98, no. 3, pp. 387-393, 2011.

[74] O. Zschenker, A. Raabe, I. K. Boeckelmann et al., "Association of single nucleotide polymorphisms in ATM, GSTP1, SOD2, TGFB1, XPD and XRCC1 with clinical and cellular radiosensitivity," Radiotherapy and Oncology, vol. 97, no. 1, pp. 26-32, 2010.

[75] D. Azria, M. Betz, C. Bourgier, W. J. Sozzi, and M. Ozsahin, "Identifying patients at risk for late radiation-induced toxicity," Critical Reviews in Oncology/Hematology, vol. 84, supplement 1, pp. e35-e41, 2012.
[76] G. C. Barnett, C. M. L. West, A. M. Dunning et al., "Normal tissue reactions to radiotherapy: towards tailoring treatment dose by genotype," Nature Reviews Cancer, vol. 9, no. 2, pp. 134142, 2009.

[77] S. Damaraju, D. Murray, J. Dufour et al., "Association of DNA repair and steroid metabolism gene polymorphisms with clinical late toxicity in patients treated with conformal radiotherapy for prostate cancer," Clinical Cancer Research, vol. 12, no. 8, pp. 2545-2554, 2006.

[78] S. De Langhe, K. De Ruyck, P. Ost et al., "Acute radiationinduced nocturia in prostate cancer patients is associated with pretreatment symptoms, radical prostatectomy, and genetic markers in the TGF $\beta 1$ gene," International Journal of Radiation Oncology*Biology*Physics, vol. 85, no. 2, pp. 393-399, 2013.

[79] L. Fachal, A. G. Gómez-Caamaño, P. Peleteiro et al., "Association of a XRCC3 polymorphism and rectum mean dose with the risk of acute radio-induced gastrointestinal toxicity in prostate cancer patients," Radiotherapy \& Oncology, vol. 105, no. 3, pp. 321-328, 2012.

[80] L. Fachal, A. Gómez-Caamaño, M. Sánchez-García et al., "TGF $\beta 1$ SNPs and radio-induced toxicity in prostate cancer patients," Radiotherapy and Oncology, vol. 103, no. 2, pp. 206209, 2012.

[81] O. Popanda, J. U. Marquardt, J. Chang-Claude, and P. Schmezer, "Genetic variation in normal tissue toxicity induced by ionizing radiation," Mutation Research, vol. 667, no. 1-2, pp. 58-69, 2009.

[82] T. Suga, M. Iwakawa, H. Tsuji et al., "Influence of multiple genetic polymorphisms on genitourinary morbidity after carbon ion radiotherapy for prostate cancer," International Journal of Radiation Oncology Biology Physics, vol. 72, no. 3, pp. 808-813, 2008.

[83] M. B. Parliament and D. Murray, "Single nucleotide polymorphisms of DNA repair genes as predictors of radioresponse," Seminars in Radiation Oncology, vol. 20, no. 4, pp. 232-240, 2010.

[84] J. A. Cesaretti, R. G. Stock, D. P. Atencio et al., "A Genetically determined dose-volume histogram predicts for rectal bleeding among patients treated with prostate brachytherapy," International Journal of Radiation Oncology Biology Physics, vol. 68, no. 5, pp. 1410-1416, 2007.

[85] J. A. Cesaretti, R. G. Stock, S. Lehrer et al., "ATM sequence variants are predictive of adverse radiotherapy response among patients treated for prostate cancer," International Journal of Radiation Oncology Biology Physics, vol. 61, no. 1, pp. 196-202, 2005.

[86] C. A. Peters, R. G. Stock, J. A. Cesaretti et al., "TGFB1 single nucleotide polymorphisms are associated with adverse quality of life in prostate cancer patients treated with radiotherapy," International Journal of Radiation Oncology Biology Physics, vol. 70, no. 3, pp. 752-759, 2008.

[87] T. Pugh, M. Keyes, L. Barclay et al., "Sequence variant discovery in DNA repair genes from radiosensitive and radiotolerant prostate brachytherapy patients," Clinical Cancer Research, vol. 15, no. 15, pp. 5008-5016, 2009.

[88] R. J. Burri, R. G. Stock, J. A. Cesaretti et al., "Association of single nucleotide polymorphisms in SOD2, XRCC1 and XRCC3 with susceptibility for the development of adverse effects resulting from radiotherapy for prostate cancer," Radiation Research, vol. 170, no. 1, pp. 49-59, 2008.

[89] G. C. Barnett, C. E. Coles, R. M. Elliott et al., "Independent validation of genes and polymorphisms reported to be associated 
with radiation toxicity: a prospective analysis study," The Lancet Oncology, vol. 13, no. 1, pp. 65-77, 2012.

[90] N. J. Vogelzang, G. W. Chodak, M. S. Soloway et al., “Goserelin versus orchiectomy in the treatment of advanced prostate cancer: final results of a randomized trial," Urology, vol. 46, no. 2, pp. 220-226, 1995.

[91] M. S. Soloway, G. Chodak, N. J. Vogelzang et al., “Zoladex versus orchiectomy in treatment of advanced prostate cancer: a randomized trial," Urology, vol. 37, no. 1, pp. 46-51, 1991.

[92] J. Seidenfeld, D. J. Samson, V. Hasselblad et al., "Single-therapy androgen suppression in men with advanced prostate cancer: a systematic review and meta-analysis," Annals of Internal Medicine, vol. 132, no. 7, pp. 566-577, 2000.

[93] K. J. Pienta and D. Bradley, "Mechanisms underlying the development of androgen-independent prostate cancer," Clinical Cancer Research, vol. 12, no. 6, pp. 1665-1671, 2006.

[94] T. K. Choueiri, W. Xie, A. V. D’Amico et al., “Time to prostatespecific antigen nadir independently predicts overall survival in patients who have metastatic hormone-sensitive prostate cancer treated with androgen-deprivation therapy," Cancer, vol. 115, no. 5, pp. 981-987, 2009.

[95] M. Hussain, C. M. Tangen, C. Higano et al., "Absolute prostatespecific antigen value after androgen deprivation is a strong independent predictor of survival in new metastatic prostate cancer: data from Southwest Oncology Group trial 9346 (INT0162)," Journal of Clinical Oncology, vol. 24, no. 24, pp. 39843990, 2006.

[96] A. J. Stewart, H. I. Scher, M.-H. Chen et al., "Prostate-specific antigen nadir and cancer-specific mortality following hormonal therapy for prostate-specific antigen failure," Journal of Clinical Oncology, vol. 23, no. 27, pp. 6556-6560, 2005.

[97] R. W. Ross, W. K. Oh, W. Xie et al., "Inherited variation in the androgen pathway is associated with the efficacy of androgendeprivation therapy in men with prostate cancer," Journal of Clinical Oncology, vol. 26, no. 6, pp. 842-847, 2008.

[98] B.-L. Chang, S. L. Zheng, G. A. Hawkins et al., "Joint effect of HSD3B1 and HSD3B2 genes is associated with hereditary and sporadic prostate cancer susceptibility," Cancer Research, vol. 62, no. 6, pp. 1784-1789, 2002.

[99] L. True, I. Coleman, S. Hawley et al., "A molecular correlate to the Gleason grading system for prostate adenocarcinoma," Proceedings of the National Academy of Sciences of the United States of America, vol. 103, no. 29, pp. 10991-10996, 2006.

[100] A. L. Teixeira, R. Ribeiro, D. Cardoso et al., "Genetic polymorphism in EGF Is associated with prostate cancer aggressiveness and progression-free interval in androgen blockade-treated patients," Clinical Cancer Research, vol. 14, no. 11, pp. 3367-3371, 2008.

[101] M. Yang, W. Xie, E. Mostaghel et al., "SLCO2B1 and SLCO1B3 may determine time to progression for patients receiving androgen deprivation therapy for prostate cancer," Journal of Clinical Oncology, vol. 29, no. 18, pp. 2565-2573, 2011.

[102] A. L. Teixeira, M. Gomes, A. Nogueira et al., "Improvement of a predictive model of castration-resistant prostate cancer: functional genetic variants in TGF $\beta 1$ signaling pathway modulation," PLoS One, vol. 8, no. 8, Article ID e72419, 2013.

[103] M. Kohli, S. M. Riska, D. W. Mahoney et al., "Germline predictors of androgen deprivation therapy response in advanced prostate cancer," Mayo Clinic Proceedings, vol. 87, no. 3, pp. 240246, 2012.
[104] B.-Y. Bao, J.-B. Pao, C.-N. Huang et al., "Polymorphisms inside MicroRNAs and MicroRNA target sites predict clinical outcomes in prostate cancer patients receiving androgendeprivation therapy," Clinical Cancer Research, vol. 17, no. 4, pp. 928-936, 2011.

[105] C.-N. Huang, S.-P. Huang, J.-B. Pao et al., "Genetic polymorphisms in androgen receptor-binding sites predict survival in prostate cancer patients receiving androgen-deprivation therapy," Annals of Oncology, vol. 23, no. 3, pp. 707-713, 2012.

[106] C.-N. Huang, S.-P. Huang, J.-B. Pao et al., "Genetic polymorphisms in oestrogen receptor-binding sites affect clinical outcomes in patients with prostate cancer receiving androgendeprivation therapy," Journal of Internal Medicine, vol. 271, no. 5, pp. 499-509, 2012.

[107] S. P. Huang, B. Bao, T. Hour et al., "Genetic variants in CASP3, BMP5, and IRS2 genes may influence survival in prostate cancer patients receiving androgen-deprivation therapy," PLoS One, vol. 7, no. 7, Article ID e41219, 2012.

[108] N. Tsuchiya, S. Narita, T. Inoue et al., "Insulin-like growth factor-1 genotypes and haplotypes influence the survival of prostate cancer patients with bone metastasis at initial diagnosis," BMC Cancer, vol. 13, no. 1, article150, 2013.

[109] I. F. Tannock, R. De Wit, W. R. Berry et al., "Docetaxel plus prednisone or mitoxantrone plus prednisone for advanced prostate cancer," The New England Journal of Medicine, vol. 351, no. 15, pp. 1502-1512, 2004.

[110] D. P. Petrylak, C. M. Tangen, M. H. A. Hussain et al., "Docetaxel and estramustine compared with mitoxantrone and prednisone for advanced refractory prostate cancer," The New England Journal of Medicine, vol. 351, no. 15, pp. 1513-1520, 2004.

[111] R. Bruno, N. Vivier, C. Veyrat-Follet, G. Montay, and G. R. Rhodes, "Population pharmacokinetics and pharmacokineticpharmacodynamic relationships for docetaxel," Investigational New Drugs, vol. 19, no. 2, pp. 163-169, 2001.

[112] I. Pastina, E. Giovannetti, A. Chioni et al., "Cytochrome 450 1B1 (CYP1B1) polymorphisms associated with response to docetaxel in Castration-Resistant Prostate Cancer (CRPC) patients," BMC Cancer, vol. 10, article 511, 2010.

[113] T. M. Sissung, R. Danesi, D. K. Price et al., "Association of the $C Y P 1 B 1^{*} 3$ allele with survival in patients with prostate cancer receiving docetaxel," Molecular Cancer Therapeutics, vol. 7, no. 1, pp. 19-26, 2008.

[114] T. M. Sissung, C. E. Baum, J. Deeken et al., "ABCB1 genetic variation influences the toxicity and clinical outcome of patients with androgen-independent prostate cancer treated with docetaxel," Clinical Cancer Research, vol. 14, no. 14, pp. 4543-4549, 2008. 


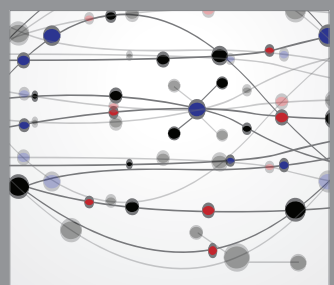

The Scientific World Journal
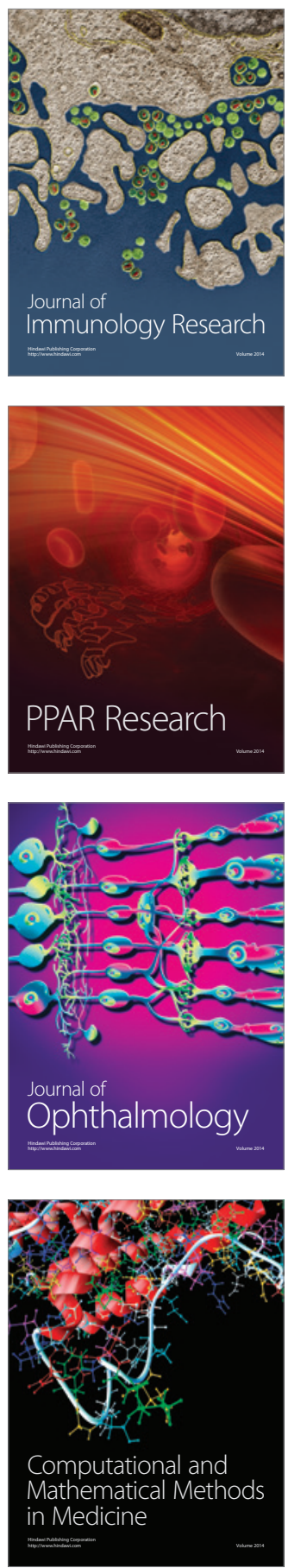

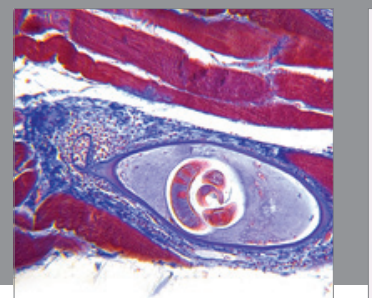

Gastroenterology

Research and Practice
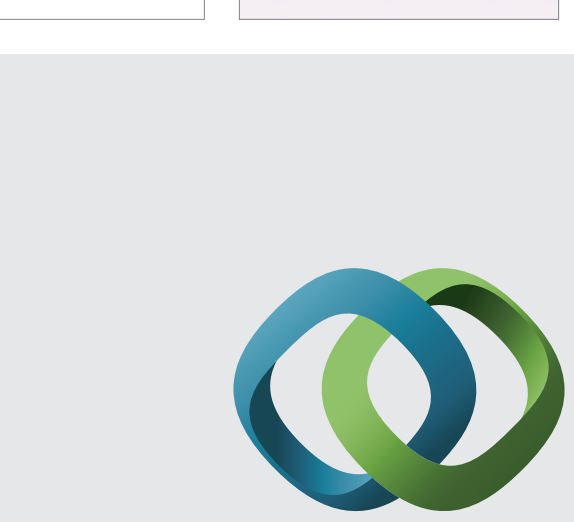

\section{Hindawi}

Submit your manuscripts at

http://www.hindawi.com
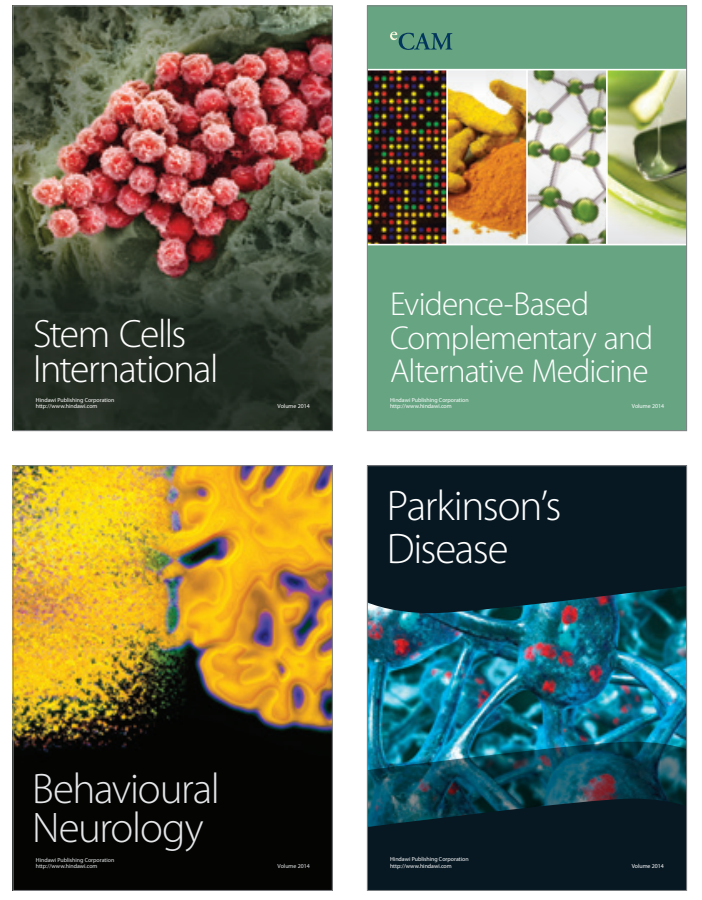
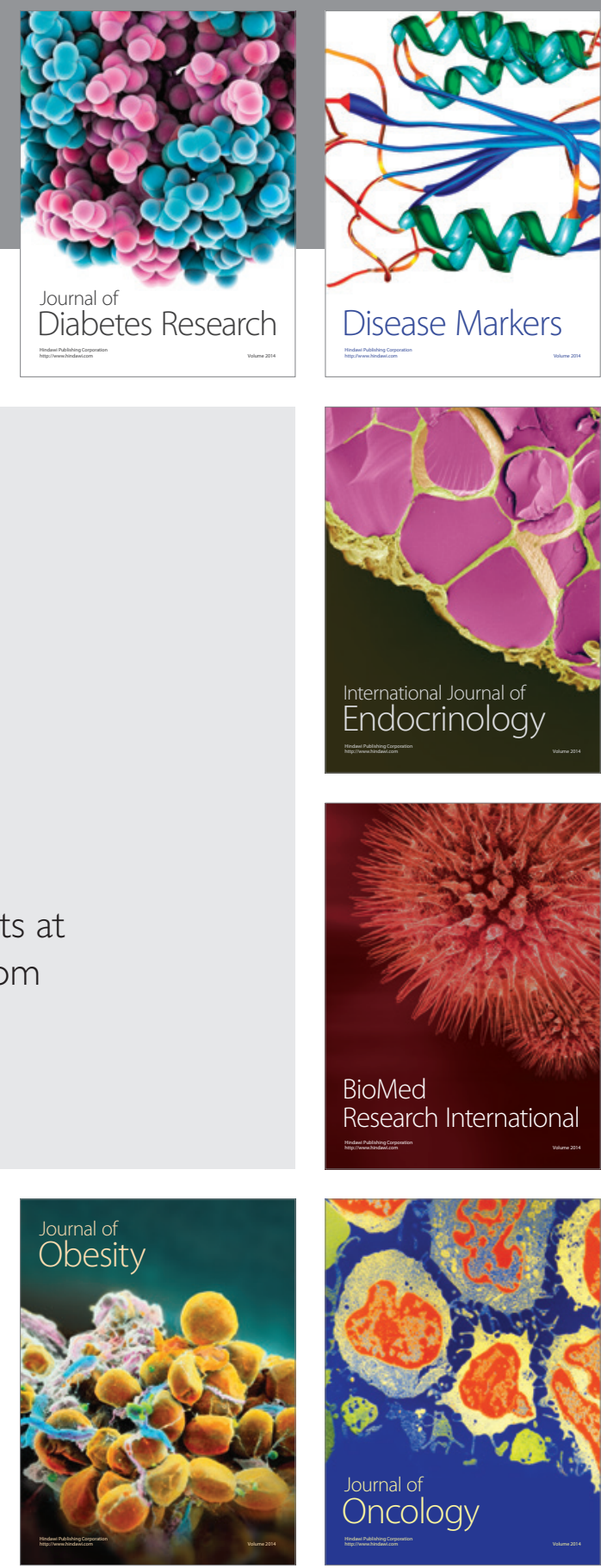

Disease Markers
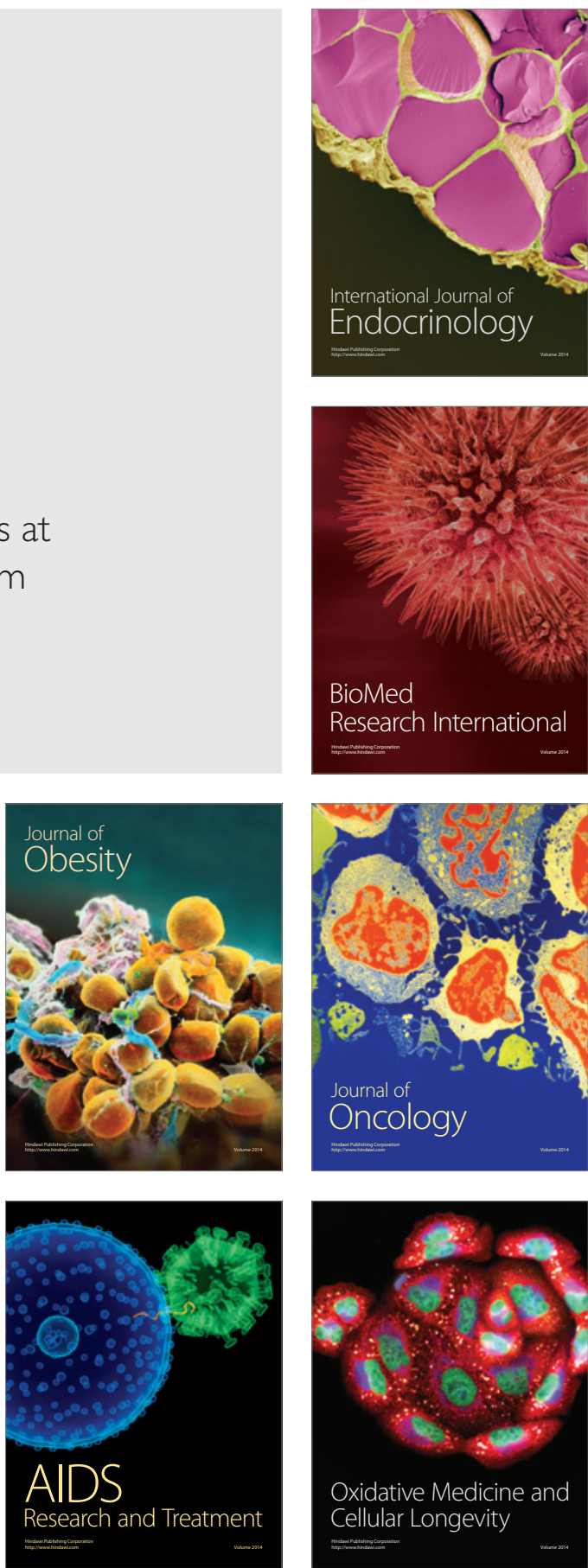